Hunter, J. I. (1922): A Mesenteric Cyst of Jejunal Origin Complicated by Retrojejunal Position of the Transverse Colon, Brit. med. J., ii, 800.

SNyder, W. H., and Choffin, L. (1954): Embryology and Pathology of the Intestinal Tract: Presentation of 40 Cases of Malrotation, Ann. Surg., 140, 368.
TRuesdale, P. E. (1935): Retroposition of the Transverse Colon, J. Amer. med. Ass., 104, 1697.

WARThen, R. O., LATtMan, I., and White, S. C. (1952): Reversed Rotation of the Bowel, Amer. J. Dis. Child., 83, 487.

TSCHERning, E. (1883): Nord. med. Ark., 15, 1, Cited by BlaCk, C. E., Tr. West. S.A., 24-87, 1915.

\title{
AN UNUSUAL CASE OF INTUSSUSCEPTION IN CHILDHOOD
}

\author{
Formerly Surgical Registrar* \\ J. D. Macfarlane, B.A.(Oxon). \\ Medical Student \\ Radcliffe Infirmary, Oxford
}

R. T. J. Holl-Allen, B.Sc., M.B., B.S.(Hons.), F.R.C.S., D.L.O.

INTUSSUSCEPTION though not common after the first year of life, can occur at any age, even sexagenarians being reported in the literature. The following case is unusual, not only is respect of age and sex, but also because of the presence of mesenteric adenitis, Meckel's diverticulum and a polyp.

\section{Case Report}

Miss S. G., age 10 years, was admitted to hospital as an emergency with a 30-hour history of anorexia, abdominal pain and vomiting. She had been quite well until the morning of the day prior to admission when she began to have central abdominal pain of a colicky nature, mainly around the umbilicus. The pain did not radiate, nor was it relieved or aggravated by coughing and change of posture. The same day she vomited several times, the vomit being watery and yellowish. In the evening it was noted that her tongue was not coated, her temperature was $97^{\circ} \mathrm{F}$, her pulse was 60 per minute, and that maximum, though slight, abdominal discomfort was just to the right of the umbilicus.

The following morning her temperature had risen to $99^{\circ} \mathrm{F}$, her pulse increased to 90 per minute, and it was noted that she had foetid breath. By the time of her admission in the afternoon her temperature was just over $100^{\circ} \mathrm{F}$, and her pulse 112 per minute. There had never been any change in her bowel habit or in the motions passed. Indeed she had passed a normal motion on the morning of admission.

Past History: She had had central abdominal discomfort on several occasions in the previous eighteen months, which had been ascribed to "nerves." These attacks were usually in the morning with no associated features, and disappeared of their own accord in about two hours.

On Examination: She was a well-developed girl. Temperature $100^{\circ} \mathrm{F}$ and pulse 112 per minute. There was a small area of deep tenderness in the abdomen just above the umbilicus where guarding and positive rebound tenderness were elicited. There was no rigidity, and no mass was palpable. The liver, spleen and kidneys were

*Present address: North Staffordshire Royal Infirmary, Stoke-on-Trent. impalpable. Rectal examination was not well tolerated; however there was no blood or mucus on the examining finger, neither was any other abnormality detected. There were no other abnormal findings on physical examination.

A provisional diagnosis of appendicitis or mesenteric adenitis was made.

Operation $(R T J H A)$ : This was performed three hours 8 after admission. A right oblique incision revealed adproximately $100 \mathrm{ml}$. of bloodstained fluid. The appendix appeared normal. There were many grossly enlarged lymph nodes in the mesentery. An ileo-ileal intussusception was found, due to an abnormality of the ileum in the region of a Meckel's diverticulum. The head of the intussusception was about 18 inches from the ileo-caecal valve (Fig. 1).

Appendicectomy was performed. The ileum was pulled through the wound, and the intussusception was reduced. Both the intussuscepiens and the intussusceptum were oedematous, and had a few dark haemorrhagic patches, but were considered still viable. However, even after the reduction, a small polypoid mass attached to he anti-mesenteric border of what was the head of the

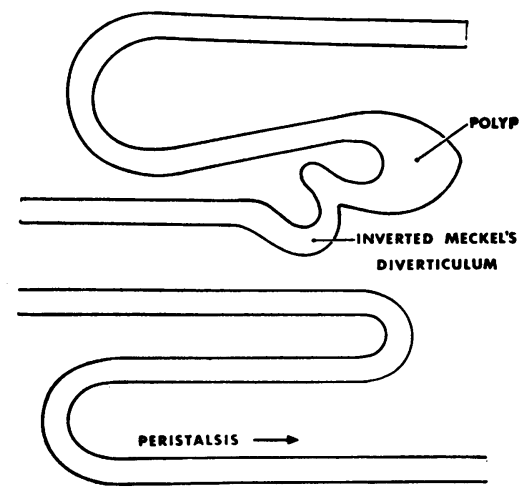

Fig. 1.-Diagram of small bowel intussusception prior to reduction. 
intussusception could be felt partially obstructing the lumen of the bowel. Beside this mass was a small diverticulum about half-an-inch long, and though difficult to identify a separate blood supply, it apparently contained all the layers of the intestinal wall, and for this reason was considered to be a Meckel's diverticulum. (Fig. 2). A portion of bowel, including these two structures, were resected, and an end-to-end anastomosis performed to restore continuity of the bowel. (Fig. 3).

Post-operatively, apart from a slight wound infection, she made a satisfactory recovery, and was discharged home on the fifteenth day.

Histological examination confirmed that the appendix was normal. Sections taken from the portion of the bowel resected showed it to be acutely inflamed with most of the wall necrotic and infiltrated with neutrophil polymorphonuclear leucocytes. In places ileal-type mucosa could be seen, but there was no evidence of gastric mucosa or pancreatic tissue. The polypoid mass attached to the base of the diverticulum was oedematous, acutely inflamed, and had an exaggerated muscularis mucosa.

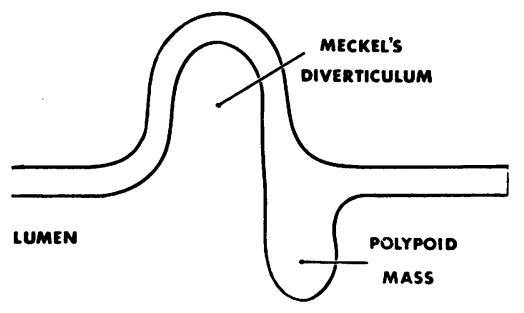

PERISTALSIS $\longrightarrow$

Fig. 2.-Diagram demonstrating the abnormalities after reduction.

\section{Discussion}

There are several forms of Meckel's diverticulum described, but it is common to limit the definition to the type where a blind sac has a lumen which communicates with that of the ileum only, and has no other attachments. It is customary to state that it is about 2 inches long, is situated about 2 feet from the ileo-caecal valve, and occurs in $2 \%$ of the population. The distribution between the sexes, as indicated by autopsy and surgical findings, is roughly equal. However, the occurrence of symptomatic Meckel's diverticula is predominant in the male, and the sex ratio ranges from $2.5: 1$ to $7.0: 1$ (Soderlund, 1956). From the figures of several authors it is apparent that the ratio of symptomatic diverticula is about $1: 2$. It seems that when Ker (1962) describes 13 cases of symptomatic Meckel's diverticula in 950 emergency operations, there must have been a large number of asymptomatic diverticula that were never found or recorded. There are several cases on record, the terminal $2 \frac{1}{2}$ feet of ileum having been examined previously, which necessitated a subsequent laparotomy to remove a diseased Meckel's diverticulum, at a distance of 4,5 or even 6 feet from the ileo-caecal valve. It is true that measurements of bowel length are notoriously difficult during operative procedures, and perhaps Mayo had this in mind when he said that a Meckel's diverticulum is frequently suspected, often looked for and seldom found.

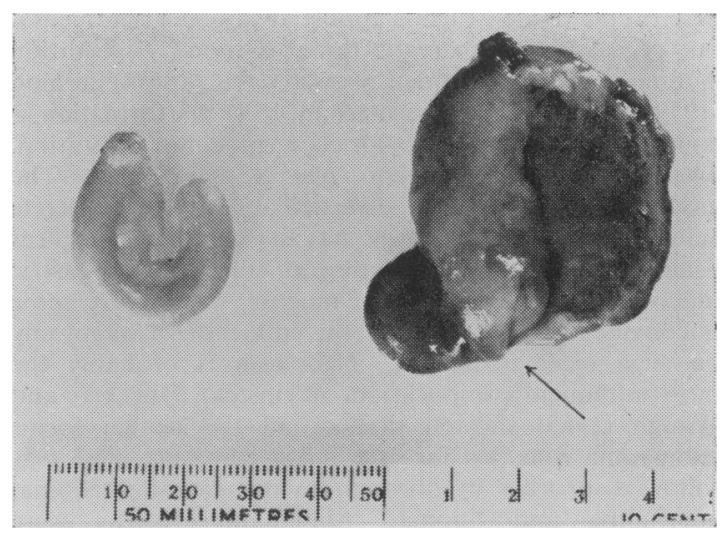

Fig. 3.-Rejected portion of bowel everted to show polypoid mass and diverticulum (arrowed)-normal appendix on left.

Symptomatic diverticula vie with the appendix in the diversity of presentation, and though several authors have listed their relative frequencies, they do not entirely agree (Christensen, 1954; Michel, Field and Ogden, 1955; Aird, 1958; Dowse, 1961 ; Bailey and Love, 1962).

Annamunthodo (1955) divides them into the following groups:-

1. Obstructive

\section{Inflammatory}

\section{Haemorrhagic - Ulcer \\ Foreign body \\ Neoplasm}

Any of the latter two groups may give rise to perforation.

There is much doubt about the frequency and diagnostic significance of haemorrhage per rectum in Meckelian diverticulitis (Taddeo and Jones, 1955; Bailey and Love, 1962; Kelley, 1962; Gracey and Williams, 1963). Varying degrees of haemorrhage in the first year of life are more an indication of intussusception than diverticulitis, but in older children, and certainly in adults, its usefulness declines. Neglecting other conditions of the bowel, it may be present in inflammation, perforation, ulceration, or in obstruction associated with a Meckel's diverticulum, the mechanism in ulceration being similar to that of peptic ulceration elsewhere in the alimentary tract. Chronic tuberculous inflammation is now virtually non-existent, but acute diverticulitis, with or without perforation, is common. Perforation ranks high in the frequency of Meckelian complications, and may follow not only inflammation but also ulceration, neoplasms, and of course, foreign bodies. MacFarlane (1948) described perforation by a cabbage stalk, and since then many bizarre objects from phytobezoar to a pin have been reported (Alhadeff, 1955; Roessel, 1962). In $20 \%$ of all diverticula there is 
heterotopic tissue which is almost always gastric mucosa, but occasionally pancreatic tissue is found. Ulceration is almost entirely confined to such cases, and Soderlund (1959) considers that the mechanism of its formation is comparable to that of pyloric or duodenal ulceration, where acid gastric contents play a major part. The gastric mucosa, in such diverticula, is able to secrete acid, and careful histology has shown that the ulcer usually forms at the junction of the ectopic gastric mucosa and the normal ileal mucosa. There are some unconvincing reports about the influence of vagotomy on such ulcer formation. Neoplasm is probably the most infrequent complication. Weinstein, Dockerty and Waugh (1963) showed that of all the benign forms leiomyoma was by far the most common, and was followed in order by fibroma, haemangioendothelioma, neurinoma and lipoma. Malignant growths were usually carcinoid, though adenocarcinoma and sarcoma also rarely occurred.

A search of the literature shows that there is little evidence for a correlation between the presence of heterotopic tissue in the diverticulum and the occurrence of neoplasm. The problem is a difficult one because of the rarity of such tumours. Soderlund (1959) in an extensive clinical and histological study of Meckel's diverticula, had not one case of malignancy in 413 cases.

Obstruction of the diverticular lumen and of the lumen of the ileum is a common sequel to inflammation, but obstruction associated with a Meckel's diverticulum may occur in the absence of any infection or inflammation. Volvulus has been described and its mechanisms discussed (Walsh, 1950; Savage, 1960; Brocklehurst and Cran, 1962), and internal herniae, with strangulation of the small intestine around a vitello-intestinal band connecting the apex of a diverticulum to the umbilicus, are well documented. Littré's hernia is commonly described in textbooks, but rarely seen in practice.

Of more immediate interest is the association of intussusception with Meckel's diverticula. Taddeo and Jones (1955) showed an incidence of diverticula in acute intussusception of $2.5 \%$. This is high when compared with the figures of Ponka (1956), 1.9\%, and Cooke and Lewis (1960), 1.5\%, though the latter authors were only dealing with children up to the age of six years. Weinstein, Cain and ReMine (1962) collected only 15 cases in a 55-year survey. Ponka (1956) implies that in all his cases the diverticulum was inverted - this is apparently the view of most authors. There are two or possibly three cases recorded where it is explicitly stated that the diverticulum was not invaginated (Soderlund, 1959). An intussusception with a Meckel's diverticulum is almost invariably of the ileo-ileal type and does not progress beyond the ileo-caecal valve, perhaps because the apex of the intussusception is too large to pass through.

Opinions vary as to whether the diverticulum invaginates as a primary or secondary feature. Soderlund (1959) thought that inversion was of two types, active and passive. In passive inversion the prime cause was the slight negative pressure that followed the passage of a food bolus through the ileum. This would tend to suck in the diverticulum and invert it. On the other hand, he considered active inversion to occur as a result of an inflammatory condition, the presence of heterotopic tissue or foreign bodies in the diverticulum, which lead to an increase in peristaltic activity by exciting the normal muscle layers. In the active process of attempting to free itself of the irritating factor, it may possibly invert. Once this inversion has taken place, it is easier to understand the development of an intussusception. The inverted diverticulum obstructs the lumen of the ileum and, like a trapped bolus, causes an increase in the motility of the bowel, especially proximally, with the result that intussusception may occur with the diverticulum at its apex. Small evidence that might be brought in favour of the active inversion is that in $10-30 \%$ of intussusceptions associated with diverticula, there is evidence of other diseases present in the diverticula. The bulk of evidence would suggest, therefore, that invagination is a primary feature. However, it must not be thought that such invagination is always followed by intussusception. Ker (1962) believes that recurrent attacks of central abdominal pain in some children may be due to repeated invaginations and spontaneous reductions of Meckel's diverticula.

Though a Meckel's diverticulum occurs in about $2 \%$ of cases of intussusception, and is almost always of the ileo-ileal variety, there must be a considerable number of cases where ileo-ileal intussusception occurs without such a diverticulum because its frequency as a type of intussusception is about $8 \%$ of all intussusceptions (Bailey and Love, 1962). This would lead one to believe that some other factors might be at work even in those cases of ileo-ileal intussusception where a Meckel's diverticulum is present.

Peck, Lynn and Dushane (1963), in discussing the aetiology of intussusception in children, thought that there was no specific precipitating factor in $81 \%$ of the cases. The other $19 \%$ were divided into two groups, those where a definite causative pathology was present, and those where a contributory pathology may have had a bearing on the condition. In the first group they included Meckel's diverticula, polypoid masses and lymphosarcomata, and in the second, hypertrophied Peyer's patches, bands, ascariasis and tumefaction of the ileocaecal valve. Cooke and Lewis (1960) suggested that anatomical features might play a part - for instance, size of ileum, the position of the ileum in the abdominal cavity and gravity.

Spasm too may be important. Occasionally at operation for intussusception abnormal peristalsis has been observed. Hadfield (1961) described three children with multiple intussusceptions in the ileum alone, or in combination with an ileo-colic intussusception, who had hyperactive bowel movement. He suggested that hyperperistalsis with localised spasm may produce an intussusception. Cooke and Lewis (1960) thought that intussusception might result from a delay in the development of the inhibitory sympathetic system, but produced no evidence.

Perrin and Lindsay (1921) argued that any theory must explain why intussusception commonly happens in children under the age of one year, and why most begin in the terminal ileum. There is a large quantity of lymphatic tissue at the ileo-caecal valve, and in the terminal ileum, in children of this age group and they showed that it decreased after the age of one year. They suggested, therefore, that the aggregation of lymphatic 
tissue might form the apex of an intussusception. Intussusception may begin at other sites where the lymphatic tissue is not so obvious, and the hypothesis of lymphoid hyperplasia forming an apex is clearly not so tenable. Perhaps intussusception may be more common than it appears, and may, particularly in these other sites, reduce spontaneously, whereas those occurring in the terminal ileum with its narrow lumen progress. (See also Watts, 1954).

If abnormal peristalsis or hypertrophied tissue is important aetiologically, what produces them? Bailey and Love (1962) have noted the association of intussusception and hypertrophied Peyer's patches in children under one year. It was thought that the change in diet was the main cause. When infants were weaned a change in the intestinal flora took place which caused hypertrophy of the lymphatic tissue in the wall of the bowel. The protrusion of this tissue partially blocked the lumen and acted similarly to a bolus of food, being propelled onwards.

Avent (1942) noted that nearly half of the children presenting with acute intussusception also had mesenteric adenitis. Nelson (1964) was careful to point out that though there was a frequent association of acute mesenteric adenitis with acute infection of the upper respiratory tract, and especially the pharynx, both acute and chronic involvement of mesenteric lymph nodes may also be associated with infections of the appendix and intestines. Ross, Potter and Zachary (1962) have recorded that mesentric adenitis was present in all 24 cases of intussusception seen in one year. They succeeded in isolating adenovirus from mesenteric nodes in 9 out of 21 cases, and no virus from any of the 15 control cases. There was no clear correlation between upper respiratory infection and isolation of virus, nor could the degree of mesenteric adenitis be correlated with the duration of symptoms before operation, or with laboratory evidence of virus infection. Clearly it is improbable that a virus infection alone could cause a progressive intussusception - if so intussusception would be common. It was noticed, however, that acute-phase sera from the children with intussusception were often negative for neutralising antibody. Potter, Sheddon and Zachary (1963) examined acute-phase serum specimens for neutralising antibody from 48 patients admitted with intussusception, with a parallel series of 171 control serum specimens. This clearly showed that children with intussusception had significantly less evidence of past infection by adenovirus than controls. This finding is specifically related to infection by the non-epidemic serotypes $1,2,5$ and 6 . Evidence of past infection by the epidemic serotypes 3 and 7 is found as frequently in controls as in cases of intussusception. They assumed the absence of neutralising antibody to be associated with susceptibility to infection by the virus or viruses. On the assumption, it is possible that an unrecognised, non-epidemic serotype, adenovirus infection is followed by lymphoid hypertrophy, hypermotility of the bowel wall (Rutten and Oudejans, 1961) or both. In some children who have a predisposition to intussusception (Steyn and Kyle, 1961) these factors could be significent to start an intussusception.

In the case presented, three separate aetiological factors could account for the findings described. These are a polypoid mass, Meckel's diverticulum and mesen- teric adenitis. The exact interrelationship, if any, is not apparent. The polypoid mass probably produced a bolus-like obstruction of the bowel, and in the manner previously described, caused the diverticulum to become inverted and intussuscepted. The mesenteric adenitis and generalised lymphoid tissue hypertrophy almost certainly were contributory factors.

Owing to the absence of rectal bleeding, and an abdominal mass, intussusception was not considered. In retrospect, Meckelian diverticulitis should have been suspected because of the steady increase in pulse rate, pain and vomiting, associated with no palpable abnormality abdominally or rectally (Gracey and Williams, 1963). With regard to the area of tenderness in this case, it again appeared to confirm the statement of Aird (1958), who thought it to be usually closer to the umbilicus than McBurney's point. This also can occur in mesenteric adenitis, the peak incidence of which is in the same age group as the patient, i.e. 8 - 12 years.

\section{Summary}

An unusual case of intussusception, associated with a polypoid mass, Meckel's diverticulum and mesenteric adenitis is reported.

The aetiology of intussusception related to these findings is discussed, together with the relevant literature.

We should like to thank Mr. G. E. Moloney, F.R.C.S., M.R.C.P. for permission to publish this case.

\section{REFERENCES}

AIRD, I. (1958): A Companion in Surgical Studies, 2ndeo Ed. Edinburgh and London: E. and S. Livingstone. AlmadefF, R. (1955): Perforation of Meckel's Diverticulum by Foreign Body and Review of the Literature, Brit. J. Surg., 42, 527.

Annamunthodo, H. (1955): Acute Complications of Meckel's Diverticulum, Postgrad. med. J., 31, 19.

AvenT, C. H. (1942): Acute Intussusception of Childhood; its Relation to Mesenteric Lymphadenitis, Sth. Surg., 11, 555.

BaIley, H. and Love, R. J. M. (1962): A Short Practice of Surgery, 12th edition. London: H. K. Lewis.

Brocklehurst, G. and Cran, I. M. (1962): An Unusual Complication of a Meckel's Diverticulum, Brit. J. Surg., 49, 604.

Christensen, E. (1954): Meckel's Diverticulum as an Abdominal Emergency, Brit. med. J., i, 1347.

COOKE, D. C., and LewIS, E. C. (1960): A Thirty Year Survey of Acute Intussusception in Childhood; 269 Cases, Lancet, ii, 1359.

Dowse, J. L. A. (1961): Meckel's Diverticulum, Brit. J. Surg., 48, 392.

Ellis, R. W. B. (1963): Diseases in Infancy and Childhood, 4th edition. Edinburgh and London: E. and $S$. Livingstone.

GraCeY, L. R. H., and Williams, J. A. (1963): Meckel's Diverticulum in Children, Brit. J. clin. Pract., 17, 315.

HADFIELD, J. (1961): Acute Intussusception in Childhood, Lancet, i, 166.

KER, H. (1962): A Muckle of Meckels, Lancet, i, 617.

Kelley, H. G. (1962): Intussusception and Bleeding Caused by Inverted Meckel's Diverticulum, Amer. J. Surg., 104, 108.

MacFarlane, D. A. (1948): Foreign Body Perforations in Meckel's Diverticulum, Brit. J. Surg., 35, 421. 
Michel, M. L., Field, R. J., and OGden, W. W. jr. (1955): Meckel's Diverticulum: An Analysis of One Hundred Cases and the Report of a Giant Diverticulum and of Four Cases Occurring Within the Same Immediate Family, Ann. Surg., 141, 819.

Nelson, W. E. (1959): Textbook of Paediatrics, 7th edition. Philadelphia and London: W. B. Saunders.

PeCK, D. A., LYNN, H. B., and Dushane, J. W. (1963): Intussusception in Children, Surg. Gynec. Obstet., 116, 398.

Perrin, W. S., and Lindsay, E. C. (1921): Intussusception: A Monograph Based on 400 Cases, Brit, J. Surg. 9, 46.

PONKA, J. L. (1956): Intussusception Due to Invaginated Meckel's Diverticulum; Presentation of Two Cases and Analysis of 52 Cases Collected from Literature, Amer. J. Surg., 92, 545.

Potter, C. W., Sheddon, W. I. H., and Zachary, R. B. (1963): A Comparative Study of the Incidence of Adenovirus Antibodies in Children with Intussusception with that in a Control Group, J. Pediat., 63, 420.

Roessel, C. W. (1962): Perforation of Meckel's Diverticulum by Foreign Body: Case Report and Review of the Literature, Ann. Surg., 156, 972.

Ross, J. G., PotTer, C. W., and ZaChary, R. B. (1962): Adenovirus Infection in Association with Intussusception in Infancy, Lancet, ii, 221.

Rutren, A., and Oudejans, E. (1961): Abdominal
Manifestations of Adenovirus Infection in Infants, Lancet, ii, 597.

Savage, P. T. (1960): An Unusual Case of Meckel's Diverticulum, Proc. roy. Soc. Med., 53, 228.

SoDERLUND, S. (1956): Meckel's Diverticulum in Children. A Report of 115 Cases, Acta. chir. Scand., $110,261$.

SoDERLUND, S. (1959): Meckel's Diverticulum: A Clinical and Histological Study, Acta. chir. Scand., Suppl., 248.

STEYN, J., and KYLE, J. (1961): Epidemiology of Acute Intussusception, Brit, med. J., i, 1730.

STRANG, R. (1959): Intussusception in Infancy and Childhood: A Review of 400 Cases, Brit. J. Surg., 46, 484.

TADDEO, M. C., and Jones, M. M. (1955): Intussusception Due to Invaginated Meckel's Diverticulum after Previous Appendectomy, Amer. J. Surg., 89, 696.

Walsh, A. (1950): Knot in Meckel's Diverticulum Causing Acute Intestinal Obstruction, Brit. J . Surg., 37, 475

Watrs, G. T. (1954): Occult Intussusception, Postgrad. med. J., 30, 655.

Weinstein, E. C., CAIN, J. C., and ReMine, W. H. (1962): Meckel's Diverticulum: 55 Years of Clinical and Surgical Experience, J. Amer. med. Ass., 182, 251.

Weinstein, E. C., Dockerty, M. B., and Waugh, J. M. (1963): Neoplasms of Meckel's Diverticulum, Int. Abstr. Surg., 116, 103.
JANe M. Fullerton, M.B., D.P.H., F.C.Path. Consultant Pathologist, St. Olave's Hospital, S.E.16.

\author{
P. Barkhan, M.D., Ph.D., M.C.Path. \\ Consultant Haematologist, Guy's Hospital, S.E.1.
}

JUST over 50 cases of acute promyelocytic leukaemia (APL) have been reported since Croizot and FavreGilly's first case in 1949. A review was published in the English literature by the French workers Bernard, Lasneret and Chone (1963), and cases have been reported from the U.S.A. by Didisheim, Trombold, Vandervoort and Mibashan (1964), and by Rosenthal (1963), but no case is reported as having occurred in Great Britain.

This form of leukaemia is characterised by a preponderance of promyelocytes, fibrinogenopaenia and a haemorrhagic, often rapidly fatal course.

This paper reports the first case of APL recorded in England.

\section{Case Report}

A 49-year-old white male storekeeper, born in England, was perfectly fit and well with no previous illnesses until three weeks prior to admission to St. Olave's Hospital on 29th September 1965.

On 11th September, he first noticed haematuria with slight loin pain, the pain being relieved by simple analgesics. He then noticed "bruises" inside his mouth, on his legs and feet and he was sent to hospital for investigation. He was admitted on 29th September.
On examination there were multiple ecchymoses. Gross haematuria was present. There was no hepatosplenomegaly or lymphadenopathy; the initial ESR was normal. The haematuria continued throughout the whole period in hospital.

The haematological and coagulation findings on admission are laid out in Tables 1 and 2. The white cell morphology is demonstrated in Figs. 1 and 2. A diagnosis of APL was made. Therapy with 6-mercaptopurine, $2.5 \mathrm{mg} / \mathrm{kg} /$ diem, with prednisolone $40 \mathrm{mg}$./diem was started on 4th October. This was supported by blood transfusions, but no remission was noted and he eventually died on 10th November, forty-two days after admission.

Necropsy. Body is that of a well built male subject showing ecchymoses on legs, arms and trunk. Brain: subarachnoid ecchymosis, but no intra-cerebral haemorrhage. Lungs: ecchymosis on pleural surfaces and the general picture was that of pulmonary oedema. The heart weighed $490 \mathrm{~g}$; no obvious pathology was present. Liver weighed $2370 \mathrm{~g}$, but appeared normal on cut surface. Spleen: firm in consistency, weighed 450 g. Gastro-intestinal tract showed petechial haemorrhages on the small intestine. Pancreas appeared normal, as did the adrenal glands, bladder and prostate. Lymph nodes were enlarged in the mesentery of the small intestine and in the right groin. The kidneys together weighed $445 \mathrm{~g}$. and there were areas of haemorrhage in the pelvis. 